\title{
ELECTRONIC SERVICES WITH IMPACT ON QUALITY OF LIFE - A SURVEY OF USAGE AND ATTITUDES OF NORTH-WESTERN CROATIAN
}

\author{
Nikolina Žajdela Hrustek ${ }^{1}$, Diana Šimić ${ }^{2}$ and Neven Vrček ${ }^{3}$
}

\begin{abstract}
Nowadays governmental and non-governmental organizations and private businesses offer a range of electronic services that, if used, directly or indirectly affect quality of life. The supply of electronic services is growing fast, and this growth is expected to continue in the near but also in the distant future. Current generation of digital natives will not know how to live without ICTs and services provided by these technologies. User attitudes towards electronic services and the relationship between their supply and demand are the focus of this paper. Data on demand for and user attitudes towards electronic services were collected on a representative sample of adult population from Northwest Croatia. Participants were interviewed using a measurement instrument created for this purpose. Survey covered usage of electronic services offered by various governmental and non-governmental organizations and private businesses, the nature of user attitudes and the extent to which electronic services are used for the purpose of education, communication, entertainment, employment, improvement of health services and culture. The results show that, on the one hand, participants' demand for electronic services is very poor, while on the other hand their motivation and attitudes towards these services are very positive. Consistently significant differences were found in usage and attitudes toward electronic services by age, level of education and English language fluency. On the other hand, gender, standard of living and urban / rural residence were generally not associated with differences in usage of or attitudes to electronic services.
\end{abstract}

\section{Introduction}

In digital revolution era the society is becoming increasingly networked and ICTs serve as one of the primary and critical forces for the improvement of quality of life. OECD Digital Economy Outlook states that, in $2014,81 \%$ of the adult population in the OECD countries' accessed the Internet, and over $75 \%$ used it on a daily basis [29, p. 136]. Large number of people are empowered by the new ICT tools, especially through a large number of electronic services offered. ICTs provide people with not only leisure and entertainment, but also with means to improve quality of life in areas of education, communication, employment, commerce, health and culture. Selwyn [34] characterizes the benefits of using ICTs as leading to social and self-understanding benefits, interaction benefits and task-oriented goals. Under self-understanding benefits, he implies, for example, increased access to current social and political affairs or information related to health. Interaction benefits comprise increased networking and social support, while task-orientated benefits include financial management, telework, travel, shopping etc.

\footnotetext{
${ }^{1}$ Faculty of Organization and Informatics, Varaždin, University of Zagreb, Croatia

${ }^{2}$ Faculty of Organization and Informatics, Varaždin, University of Zagreb, Croatia

${ }^{3}$ Faculty of Organization and Informatics, Varaždin, University of Zagreb, Croatia
} 
Numerous positive examples have demonstrated that the use of ICTs, and especially electronic services, brings great social benefits, especially to those with lower income, people with low levels of education, the unemployed, older people or those remote from physical distribution points of public services $[3,19,30]$. The disadvantaged, in one way or another, are arguably those who would benefit the most from public and private business electronic services, presuming they are familiar with ICTs. Active participation in the information society for such a group of people would result in improvement of social relationships, improvement of job possibilities and, in general, in active participation in all other spheres of society. Therefore, one of the basic government tasks in implementing active policies and strategies related to digitalization and the transformation into an information society is to identify such people and provide assistance in their socialization and integration into information society [20]. Throughout the years, European Commission has, in many policies and programmes [13, 14, 16, 17], emphasized the importance of inclusion of the most sensitive society groups, such as the elderly (called e-ageing), disabled persons (called eaccessibility), ethnical minorities, and/or those living in remote regions (and are subject to the geographical digital divide) in areas such as civic participation (e-government) and public welfare (e-health). Electronic services created for these vulnerable population groups have a potential to improve quality of life in many aspects.

\section{Areas where electronic services can improve quality of life}

Quality of life is a complex and multidimensional concept and is difficult to define because each discipline (economics, health, psychology, etc.) defines its in own way. All definitions agree in one that the quality of life is higher if people have a happy and satisfactory lives. Through years, research was found that quality of people's life depends not only on the economic prosperity of the national economy and satisfactory material and financial conditions, but also on many other factors. Some of these factors are for example education, health, entertainment, housing conditions, culture, etc. According to the Eurostat report "Quality of life — facts and views" identified areas of quality of life are: natural and living environmen, governance and basic rights, economic and physical safety, social relations and leisure, material living conditions, productive or main activity, health and education [18]. Today's modern civilization places great importance on the quality of life and improvement of quality life. For improvement quality of life an critical role have government of national economies and policies implemented. Nowadays, governments of both developed and developing countries have recognized the importance of electronic services and their potential to improve quality of life, and enhance economic and social growth and development [24, 26, 37]. Nurmela et al. [28] identify seven areas in which ICTs can improve quality of life: personal business from distance, automatic information and process system, mass media and media culture, personal production/self-expression, communication and search for information. The study assumes the following: a) devices make everyday life easier because communication can intensify, diversify and expand beyond temporal and geographic obstacles; b) devices lower the participation threshold because obtaining information is easier and opinions can be expressed through several channels [28]. A similar conclusion was made by Shih and Venkatesh [35] who have also divided the improvement of quality of life of people through the use of ICTs in seven categories: work related, family communication, family recreation, home management, home shopping, education/learning, information centre. In the project "Transformative Use of ICT in EU Regions" Gareis and Lamp [18, p. 45] identified eight areas of activities in which using ICTs improves quality of life: communication and social interaction, perception of information, retrieval of information, personal business, transactions and requests for assistance, entertainment, generation and distribution of usercreated content, participation in policymaking and public life, employment-related activities. In an attempt to establish a link between the use of ICT and its positive impact on the quality of life 
Amichai-Hamburger and Furnham [2] concluded that as technological devices enter into individual and collective spheres, ICT promotes higher social coherence, the recognition of being a part of a group. Strong attachment within a group/community enhances the members' mutual understanding and social approval and helps to raise the sense of actualization. The impact of electronic services on quality of life of individuals who use ICTs is difficult to isolate and quantify. In this study, we monitor it through the aspects of frequency of use, user attitudes and motivation to use electronic services in the areas of education, employment, communication, government, commerce, entertainment, culture and health.

\subsection{Education}

Through time, the concept of education has been changing. Nowadays education and lifelong learning are key factors and the basis for inclusion in the information society. A growing array of educational electronic services offer opportunities for lessons individually adjusted to the student's needs in ways that the classic way of teaching never could [36]. In his empirical research, Van Dijk [38] shows that the use of ICT has positive effects on learning and cognitive development through interactive learning styles, by supporting new multimedia ways of presenting information. Surprising fact, according to the OECD Digital Economy Outlook 2015 [29], is that the majority of students use computer for practicing and drilling sessions once or twice a month, and that percentage of students using computers for this purpose on a daily basis, for example, in Denmark is around $12 \%$, in Norway $10 \%$, and only $2 \%$ in Germany and Finland. The same report states that online opportunities for professional development, such as massive open online courses (MOOCs) are underutilized. In European Union in 2013 around $7.8 \%$ of Internet users attended online courses, although this percentage varied from $16 \%$ in Finland to less than $3 \%$ in the Czech Republic $[29$, p. 142, 143].

\subsection{Employment}

Opportunities for learning offered by the Internet eventually contribute to increase in employability and better salary prospects in the labour market. The opportunities for a satisfactory working life are reflected in an important ICT trend, nowadays termed e-employment. The concept of e-employment comprises broadband connection between job seekers and employers worldwide, videoconferencing, remote training and other forms of home-based or mobile-based teleworking. Electronic services in this area enable effective job searching, increase employability and business start-up [6]. According to Drever and Hoffmeister [9], the extent to which an individual is able to establish diverse social connections can be an important factor in their successful incorporation into the labour market.

\subsection{Communication}

Social relations are very important for the functioning of individuals and society as a whole. During the larger part of the $20^{\text {th }}$ century, most communications were face to face, via telephone or through physical mail. Quantity and speed of information exchange were limited by geography, technology and cost. Today Internet increases opportunities related to communication and ICTs are increasingly becoming ubiquitous. Internet service most commonly used for communication is e-mail. OECD [22, p. 139] reported that during 2013-2014, on average, 87\% of Internet users sent e-mails. Communication services are still constantly evolving. Today's technology enables affordable textual, audio and/or visual communication in real time through Internet services like Google Voice, Skype, WhatsUpp, Viber etc. Social networks provide individuals with an 
opportunity to establish new or enhance old contacts and create and maintain connections with various social groups and organizations [30]. The evolution of communication, among other things, offers easy access to broad audience. Web 2.0 applications, like forums and blogs, enable users to create their own digital communication objects. Access to mass communication enabled that new ICT and Internet technologies have created stronger connection between commerce, banking, entertainment and communication area.

\subsection{Government}

Electronic services also play a considerable role in simplifying interactions between citizens and public authorities thanks to the digitalization and automatization of many processes. The overall share of citizens that use Internet to perform administrative procedures has increased in recent years. However, still not sufficiently, as confirmed by the OECD report [29, p. 51 that states that, on average, only $35 \%$ of users in OECD countries use e-government services. ICTs likewise enable individuals to engage in collective behaviour and form social movements $[1,6,29]$.

\subsection{Commerce}

Electronic services offer consumers access to global network of suppliers and in this manner, expand the degree of consumer choices. With a wide range of search engines and price comparison sites, consumers can also reduce the time and cost spent finding goods and services. Increased capacity for consumers to find and compare products not only increases efficiency of matching customers and sellers, but also drives up price competition which can also lead to significant monetary savings. In order to satisfy the wishes and needs for products and services, electronic services provide great benefits for consumers in terms of accessing information about products and services from any part of world, as well as the possibility of purchasing them. Research conducted by the OECD shows that over 2013-2014, on average, $82 \%$ of customers in OECD countries used the Internet to obtain information on goods and products, $58 \%$ of them ordered products online, while only $21 \%$ sold products over the Internet [29, p. 139]. E-banking is one of the most successful services in e-commerce with an increasing number of users every year. As an example, according to OECD in 2013, 60\% of Internet users in OECD countries used online banking, up from $42 \%$ in 2011 and $31 \%$ in 2007 [29, p. 55].

\subsection{Entertainment}

The area where electronic services play a major role in improving the quality of life nowadays, especially for the younger population, is entertainment, specifically called e-entertainment. According to Ronchi [33, p. 9], "e-entertainment involves supplying digitalized entertainment products and services which entertain the users in a variety of languages and in line with diverse cultures, supporting data transfer, interactive entertainment of synergy between analogue and digital platforms". Various forms of electronic services and tools are available for the purpose of entertainment, while the types of electronic services in the field of e-entertainment that are most commonly used nowadays are social networking (Twitter, YouTube, Instagram, Facebook), content download (movies, music, etc.), music players, on-line gaming, etc. [4]. According to PricewaterhouseCooper Consulting, research revenues from digital entertainment are continuously growing and they forecast that by the $201865 \%$ of global entertainment and media growth - almost two in every three extra dollars - would be from digital entertainment [32]. 


\subsection{Culture}

Use of electronic services has caused major changes in the area of culture. Borders no longer exist and the culture and cultural events have now become accessible to all. Still, ICTs are continuously changing the methods of consumption of cultural products. Ubiquitous digitalization has enabled access and distribution of large amounts of cultural information to many users regardless of time and place. Virtual museums provide access to cultural heritage located in remote or difficult accessible museums. Locating literature on any topic is facilitated through online search of a library catalogue or access to a digital library where content is available in digital form. Artwork of the world's most renowned artists can be viewed and studied from home through digital galleries. All of the above can be summarized by the concept of e-culture or digital culture. According to Ronchi $[33$, p. 9] e-culture "involves preserving and presenting cultural heritage in line with the challenges of the future, exhibiting valuable cultural assets clearly and informatively using state-of-the-art technology".

Due to high availability of information that Internet provides, people can share knowledge, explore and better understand other cultures. In other words, Internet contributes to the creation of an umbrella cosmopolitan culture necessary for communication among people from disparate cultures [22]. In the European Union "digitisation and online accessibility of cultural material and digital preservation" are among political priorities. European Commission supports digital culture through open coordination of member states activities and provision of European Structural and Investment Funds $[11,15]$. Already there is a large supply of applications and tools, interactive information systems with user friendly navigation techniques, virtual reality methods and various multimedia tools and services for easier retrieval and better presentation of digital cultural contents to the users.

\subsection{Health}

One of the most outstanding benefits of implementation of electronic services is in the field of health care. Owing to ICTs health care practitioners can remotely assist or monitor vital parameters of patients anywhere and anytime. Assistive technologies play an important role in health care. Ehealth and a large number of aforementioned assistive technologies that are already available are the response to critical social challenges at significantly reduced social cost [10]. Many studies report on benefits of ICT and assistive technologies for the elderly and people with disabilities. These technologies enable target groups to reach autonomy, and maintain dignity and independent living $[21,25,27]$. To summarize, one can conclude that use of electronic services gives people a wide variety of choices and opportunities enabling them to get the kinds of products and services that best fit their desires and needs.

\section{Research design and methodology}

The main part of the survey was conducted on a representative sample of 427 adults (18+ years) from two counties in Croatia (Varaždin and Međimurje County). The sample was designed as a proportionate stratified random sample from the list of households maintained by the Croatian Bureau of Statistics originating from the 2011 Census of Population, Households and Dwellings in The Republic of Croatia. Fieldwork was carried on during December 2014 and January 2015 and comprised face-to-face oral interviews conducted by eleven qualified interviewers. We have developed a measurement instrument (a questionnaire) comprising 78 items related to digital economy (25 items), e-learning (6 items), e-health (17 items), e-government (15 items), e-culture, ecommunication and e-entertainment (15 items). Items were coded on a 5-point semantic ordinal 
scale. Response labels for items measuring user attitudes ranged from "1-strongly disagree" to "5strongly agree", and those for measuring service usage ranged from "1-not at all" to "5-very frequently". These 78 items were supplemented with socio-demographic data on participants' age, gender, place of residence, employment status and infrastructure indicators.

Qualitative and quantitative content validity of the measurement instrument were assessed by a panel of experts from Croatia and Austria. Qualitative content validity assessment resulted in recommendations on format and choice of items (e.g. selection and order of words, etc.). Quantitative content validity was assessed based on Content Validity Ratio (CVR) and average value of relative importance. For the purposes of quantitative validation, questionnaire was piloted on a convenient sample of participants contacted by electronic mail, social network (Facebook) and the e-learning system of Faculty of organization and informatics. The data collection period via an online survey lasted three months, i.e. from June to September 2014. Even though 331 respondents initiated the online survey, there were only 197 complete responses that were retained for the analysis. Assessment of construct validity of measuring instrument (questionnaire) was based on exploratory factor analysis using maximum likelihood method with orthogonal Varimax rotation and Keiser normalization. We used Kaiser-Meyer-Olkin (KMO) test and Bartlett's test of sphericity to assess sampling adequacy [21]. Fit of the model was independently evaluated with the percentage of nonredundant residuals with absolute values grater then 0.05 [8]. Internal consistency was determined by Cronbach's alpha.

In addition to standard descriptive statistics, ANOVA was used to test whether there were any differences in factor scores for usage and attitude by age, gender, household standard of living, household structure, level of education, place of residence, employment status and English language fluency. Since there were 64 comparisons we also used Benjamini \& Hochberg's correction to control the false discovery rate [5].

\section{Results}

\subsection{Validity of the measuring instrument}

Following the qualitative and quantitative content validity analysis, 10 items were reformulated and 41 items were excluded thus reducing the number of items from 78 to 37. Kaiser-Meyer-Olkin measure of sampling adequacy $(\mathrm{KMO}=0.755)$ and Bartlett's test of sphericity $(\chi 2=2237.524$, $\mathrm{df}=300, \mathrm{p}<0.0005)$ both confirmed that assumptions for exploratory factor analysis were met. Number of non-redundant residuals $>0.05$ in absolute value was $10(3,0 \%)$ confirming that the model represents data well. We have retained 8 factors that accounted for $73.34 \%$ of total variance. Number of manifest variables was further reduced from 37 to 25. Table 1. shows Cronbach's alpha coefficients for subscales of the measurement instrument. All subscales had satisfactory reliability. 


\begin{tabular}{lc}
\hline \multicolumn{1}{c}{ FACTOR } & CRONBACH'S ALPHA \\
\hline FACTOR 1 - e-learning & 0.823 \\
FACTOR 2 - e-health (usage) & 0.822 \\
FACTOR 3 - e-government & 0.878 \\
FACTOR 4 - e-health (attitude) & 0.835 \\
FACTOR 5 - e-culture & 0.753 \\
FACTOR 6 - e-entertainment & 0.704 \\
FACTOR 7 - e-employment & 0.801 \\
FACTOR 8 - e-banking, e-commerce, e- communication & 0.625 \\
\hline
\end{tabular}

Table 1: Cronbach's alpha coefficients for 8 subscales

\subsection{Usage and attitudes towards electronic services}

In the main part of the survey, 427 respondents participated voluntary in the research and have completed the questionnaire. There were 185 (43.3\%) male and $242(56.7 \%)$ female participants. The greatest portion consisted of participants aged between 45 and 54 years $(76$, or $17.8 \%)$ and the smallest portion of participants were participants with age 75 years and older (36, or 8.4\%). Majority of participants (228, or 53.4\%) are from a rural area, $116(27.2 \%)$ of respondents live in an urban and $83(19.4 \%)$ in a suburban area. Large majority $(299$, or $70.0 \%)$ of respondents use fixed Internet access at home, and $179(41.9 \%)$ use mobile Internet access. More than 80\% (353 respondents) own a mobile device, $219(51.3 \%)$ have a laptop and more than $50 \%$ of all respondents stated they own a desktop computer. Respondents use ICTs for educational purposes fairly little. More than three quarters $(327$, or $76.6 \%)$ of respondents declared they "do not at all" or "very rarely" use ICTs for information search about educational courses. Only 48 (11.2\%) respondents do it "frequently" or "very frequently". Similar results were obtained for use of ICTs to access and download materials for education/training (311 or 72.8\% "very rarely" or "not at all", 22 or 5.2\% "very frequently"). Only 30 respondents (7.0\%) attend online educational courses "frequently" or "very frequently", while 287 (67.2\%) respondents declared they do it "not at all".

In Croatia, e-health services (factors 2 and 4) have been available for several years but the frequency of use is quite low, similar to e-education services. Thus, for example, only $55(12.9 \%)$ respondents "frequently" or "very frequently" use Internet to obtain a second opinion regarding diagnosis and health status for friends or family members, while $325(76.1 \%)$ have used it for this purpose "never at all". Only $23(5.4 \%)$ respondents "frequently" or "very frequently" use Internet to get a specialist examination or surgeries, while $337(78.9 \%)$ have never used these services. A very small number of respondents (75 or 17.6\%) use Internet "frequently" or "very frequently" for information search to improve their health, while $286(67.2 \%)$ have "never used" or use it "very rarely". Use of Internet to search for information about medicines or to buy medicines is also poor. $317(74.2 \%)$ respondents declared to have "never" or "very rarely" used Internet for this purpose, and only $52(12.2 \%)$ respondents stated they use it "frequently" or "very frequently". However, examining the attitudes concerning the fact that e-health increases the quality of health services (36.30\%), saves time (38.18\%) and is more cost acceptable $(38.40 \%)$, if compared to the alternative traditional ways, the majority of respondents' attitude is positive. Whereas regarding the claim "I would recommend the use of e-health care to other users", more than $55 \%$ of respondents have either a positive or negative opinion which can be explained by the aforementioned low frequency of use of this type of service. 
The results for e-government (factor 3) show that the respondents who participated in this survey have positive attitudes toward the need for creating new governmental e-services. Thus $286(67.0 \%)$ respondent agree that electronic services should be used for applications related to land registry, cadastre, and building permits, 276 (64.6\%) agree with using electronic services for birth and citizenship certificates, and the same number agree with using electronic services for requesting marriage certificates. The same number of respondents also "agree" or "strongly agree" that there should be electronic services for requesting passports, driving licenses, identity cards and other documents. Positive attitude ( 265 or $62.1 \%$ of respondents) is also connected to the claim "I believe that the filing tax return forms should be enabled by using ICT and the Internet.", and 281 (65.8\%) respondents agree that ICTs should be used for residence registration.

Respondents practically do not use ICTs for e-culture (factor 5). As many as 350 (82.0\%) respondents do not use ICTs to watch theatrical performances, and $34(8.0 \%)$ use them very rarely. Even more respondents (401 or 93.9\%) do not "visit museums online. A surprising fact is that only $38(8.9 \%)$ respondents read / download digital books "frequently" or "very frequently".

Surprisingly, even for e-entertainment (factor 6), usage of electronic services is very low. Very large number of respondents "rarely" or "very rarely" use ICTs to: "read online newspapers, magazines..." (242 or 56.7\%), "listen / download music" (279 or 65.3\%), "watch / download movies" (305 or $71.4 \%$ ), "watch TV shows" (363 or 85.0\%) and "listen to radio station" (369 or $86.4 \%)$.

A very low usage of ICTs for employment purposes (factor 7) was also observed. Number of respondents who "do not" use, use "rarely" or "very rarely" ICTs "to find information about employment" was 368 (86.2\%), "to send job applications" was $396(92.7 \%)$ and "to log on portals for employment services" was 386 (90.4\%).

Factor 8 comprises e-commerce, e-banking and e-communication. Again, a small number of respondents use ICTs for "online shopping" (92 or 21.5\%) or "to buy / book tickets (concerts, theatre, exhibitions)" (32 or 7.5\%). Slightly larger number "search information on desired products and services" (157 or 36.8). E-banking is one of the most popular e-services in the area of ecommerce, still 295 (69.1\%) respondents stated they "do not" use it, or use it "rarely" or "very rarely". E-mail is used as a form of communication "frequently" or "very frequently" by only 165 $(38.6 \%)$ respondents, while social networks (e.g. Facebook, Twitter...) are used "frequently" or "very frequently" by $138(32.3 \%)$ respondents.

\subsection{Variation of factor scores in relation to socio-demographic characteristics}

We used ANOVA to compare mean factor scores across levels of eight socio-demographic variables. Results are summarized in Table 2. 


\begin{tabular}{|l|c|l|l|l|l|l|l|l|}
\hline & \multicolumn{9}{|c|}{ Factor scores } \\
\hline Socio-demographic factors & I & II & III & IV & V & VI & VII & VIII \\
\hline Gender (df1=1; df2=425) & NS & NS & NS & NS & NS & $*$ & NS & $*$ \\
\hline $\begin{array}{l}\text { Household standard of living } \\
\text { (df1=4;df2=422) }\end{array}$ & NS & NS & NS & NS & NS & $*$ & $*$ & $* *$ \\
\hline Age (df1=6;df2=420) & $* * *$ & $* * *$ & $* * *$ & $*$ & $* * *$ & $* * *$ & $* * *$ & $* * *$ \\
\hline Household structure (df1=1; df2=420) & $* * *$ & $* *$ & $*$ & NS & $* * *$ & $* * *$ & $* * *$ & $* * *$ \\
\hline Level of education (df1=6;df2=420) & $* * *$ & $* * *$ & $* * *$ & $* * *$ & $* * *$ & $* * *$ & $* * *$ & $* * *$ \\
\hline Place of residence (df1=2; df2=424) & $* *$ & NS & NS & NS & NS & NS & NS & NS \\
\hline Employment status (df1=6; df2=420) & $* * *$ & $* *$ & $* * *$ & NS & $* * *$ & $* * *$ & $* * *$ & $* * *$ \\
\hline English language fluency (df1=5;df2=421) & $* * *$ & $* * *$ & $* * *$ & $* * *$ & $* * *$ & $* * *$ & $* * *$ & $* * *$ \\
\hline $\begin{array}{l}\text { Legend: } \\
*\end{array} \quad<0.05 * *$ p $<0.01 \quad * * *$ \\
$\begin{array}{l}\text { Factors: I }<0.001 \\
\text { e-entertainment, VII - e-employment, VIII - e-banking, e-commerce, e-communication }\end{array}$
\end{tabular}

Table 2: Summary of the results of ANOVA for eight factor scores (sub-scales) by socio demographic factors, with Benjamini \& Hochberg's correction for false discovery rate [5].

Only for factors 6 and 8 (e-entertainment and e-commerce) was there a significant difference in factor scores between genders, with higher average scores in males. When it comes to standard of living, significant difference among the 5 levels of standard were found for factors 6 to 8 . E-entertainment and e-commerce followed the same pattern of higher scores for higher standard of living, while e-employment showed the opposite trend. Differences in mean factor scores among age groups are significant for all factors. In general, there is a trend of decrease in mean factor scores with growing age. For factors 3 (e-government) and 8 (e-banking, e-commerce, ecommunication) the youngest age group (18-24 years old) shows slightly lower mean factor scores than the second age group (25-34 years) with decrease in factor scores for older groups. Factor 4 (attitude towards e-health) shows steady level for younger to middle age groups (up to 54 years) and then starts decreasing, like other factor scores. Differences in factor scores among groups defined by household structure are significant for all factors except factor 4 (e-health attitudes). For all these factors, higher factor scores were observed in households with children. All factors exhibit significantly higher factor scores in groups with higher levels of education. Only for e-learning usage was there a significant difference among places of residence, with urban population showing higher usage than suburban and rural populations. Only for factor 4 (e-health attitude) there was no significant difference in mean factor score by employment status. For all other factors except eemployment (factor 7) there was a similar trend of increase in factor scores from retired people, to unemployed, fully employed, with maximum mean factor score for students. For e-employment (factor 7) the highest mean score was observed in those with temporary part-time jobs, followed by unemployed and students. All factor scores increase significantly with higher level of English language fluency.

\section{Summary and conclusion}

Our aim was to study citizens' attitudes to and usage of e-services in eight areas that have a significant impact on quality of life: economics, education, employment, health, government, culture, communication and entertainment. Usage of ICTs for education, employment, health and culture was very low. On the other hand, in economics, communication and entertainment, ICTs were most often used to search for information about products and services. Online shopping is still not preferred by as many as $78.0 \%$ of respondents. Usage is slightly better in e-entertainment with $34.7 \%$ of the respondents using ICTs frequently or very frequently for listening/downloading music, 
$28.6 \%$ for watching/downloading movies, but less than $15.0 \%$ of respondents use it for listening to radio stations and watching TV shows. While e-mail is used for communication very rarely by $54.1 \%$ of respondents, $60.7 \%$ do use social networks (such as Facebook, Twitter, etc.). The least often used electronic services were shopping and booking of tickets for concerts or theatre shows (only $7.5 \%$ of respondents do it frequently or very frequently). General attitude toward e-health services was undecided with majority of the respondents having neither positive nor negative opinion, or else not having an opinion at all. This can be explained by extremely low usage of ehealth services. Respondents' attitudes toward development of new e-government services was generally positive. According to information published on the central e-government portal this is in line with long term plan of Directorate for e-Croatia of the Ministry of Public Administration. Citizens in Croatia have generally positive attitude concerning e-services, even though usage is very poor. Age, level of education, and English language fluency were the most significant determinants of factor scores for usage and attitude subscales. Household structure and employment status were associated with differences in usage and attitudes for all subscales except those for e-health. On the other hand, gender, standard of living and rural vs. urban residence did not in general significantly determine factor scores of usage and attitudes subscales.

Results point to high level of availability of fixed and/or mobile access to Internet, and mobile devices in studied population. Even though attitudes to use of electronic services are generally positive, usage is still very low. The most important barrier to increased usage seem to be lack of digital literacy, as level of education, age and English language fluency were the most significant determinants of usage and attitudes. We would recommend the Government to introduce informatics as an obligatory subject in primary and secondary education and organize free or affordable workshops on use of Internet services for general population (especially the elderly). Additionally, promotion of available services through newspapers, public television, and other forms of marketing could improve citizens' motivation to use electronic services.

\section{References}

[1] ALI, A. H.: The Power of Social Media in Developing Nations: New Tools for Closing the Global Digital Divide and Beyond. Harvard Human Rights Journal, 24, 2011, 185-219.

[2] AMICHAI-HAMBURGER, Y. and FURNHAM, A.: The positive net. Computers in Human Behavior, 232, 2007, 1033-1045.

[3] BANKOLE, F. O., SHIRAZI, F. and BROWN, I.: Investigating the impact of ICT investments on human development. The Electronic Journal of Information Systems in Developing Countries 48 8, 2011, 1-19.

[4] BENEDETTO, S., CORREIA, L. M. and LUISE, M.: The Newcom++ Vision Book. Springer, Berlin, Heidelberg, 2012.

[5] BENJAMINI, Y. and YEKUTIELI, D.: The control of the false discovery rate in multiple testing under dependency. Annals of Statistics 29, 2001, 1165-1188.

[6] CODAGNONE, C., CILli, V., BIAGI, F., FOLEY, P. and DE LUCA, A.: Inclusive Innovation for Growth and Cohesion: Modelling and demonstrating the impact of eInclusion. European Commission, Directorate-General for Communications Networks, Content and Technology, Bruxelles, 2009. DOI 10.2759/51002. 
[7] CONROY M., FEEZELL, J. T. and GUERRERO, M.: Facebook and political engagement: A study of online political group membership and offline political engagement. Computers in Human Behavior, 28, 2012, 1535-1546.

[8] CURETON, E.E. and D'AGOSTINO, R.B.: Factor analysis: an applied approach, Psychology Press, New York, 2009.

[9] DREVER, A. I. and HOFFMEISTER, O.: Immigrants and social networks in a job-scarce environment: The case of Germany. International Migration Review. 42, 2, 2008, p. 425-448.

[10] ECCLES, A., DAMODARAN, L., OLPHERT, W., HARDILL, I. and GILHOOLY, M.: Assistive Technologies: Ethical Practice, Ethical Research, and Quality of Life, in: Technologies for Active Aging. Springer US, 2013, 47-68.

[11] EUROPEAN COMMISSION. e-Health - making healthcare better for European citizens: An action plan for a European e-Health area. COM (2004) 356 final. Brussels. 30 April, 2004.

[12] EUROPEAN COMMISSION (EC). Digital Culture. Access to and preservation of cultural heritage, Brussels, 2004.

[13] EUROPEAN COMMISSION (EC). Towards an accessible information society. COM (2008) 804, Brussels, December 2008.

[14] EUROPEAN COMMISSION (EC). The Active and Assisted Living Joint Programme (AAL JP) 2013-2020, https://ec.europa.eu/digital-single-market/node/50829, 10.11.2016.

[15] EUROPEAN COMMISSION (EC). Implementation of Commission Recommendation on the digitisation and online accessibility of cultural material and digital preservation Progress report 2013-2015, Brussels, 2016.

[16] EUROPEAN COMMISSION (EC). The European eGovernment Action Plan 2011-2015. Harnessing ICT to promote smart, sustainable \& innovative Government, COM(2010) 743 final, Brussels, 2010, 10.11.2016.

[17] EUROPEAN COMMISSION (EC), Communication from the Commission to the European Parliament, the Council, the European Economic and Social Committee and the Committee of the Regions: EU eGovernment Action Plan 2016-2020 Accelerating the digital transformation of government (COM(2016) 179 final), Brussels, April 2016.

[18] EUROSTAT, Quality of life in Europe - facts and views, 2015, http://ec.europa.eu/eurostat/ documents/3217494/6856423/KS-05-14-073-EN-N/, 19.03.2017.

[19] GAREIS, K. and LAMP, H.: WP2: Indicators on Transformative Use of ICT- D2.1 Indicator Stocktaking Report, 2007, http://www.transform-eu.org/publications/documents/D2.1.pdf, 02. 11.2016 .

[20] HANNA, N. K.: An ICT-Transformed Government and Society. In: Transforming Government and Building the Information Society, Springer, New York, 2011, 1-25. 
[21] HARDEY, M. and LOADER, B.: The Informatization of Welfare: Older People and the Role of Digital Services. British Journal of Social Work. 39, 2009, 657-669.

[22] HONGLADAROM, S.: Global Culture, Local Cultures and the Internet: The Thai Example. Ai \& Society.13, 4, 1999, 389-401.

[23] HUTCHESON, G. and SOFRONIOU, N.: The multivariate social scientist. Sage. London. 1999.

[24] KOZMA, R. B.: National policies that connect ICT-based education reform to economic and social development. An Interdisciplinary Journal on Humans in ICT Environments. 1, 2, 2005, 117-156.

[25] LOADER, B. D., HARDEY, M. and KEEBLE, L.: Health informatics for older people: a review of ICT facilitated integrated care for older people. International Journal of Social Welfare. 171, 2008, 46-53.

[26] MADON, S.: The Internet and socio-economic development: exploring the interaction, Information Technology \& People, 13, 2, 2000, 85-101.

[27] MORT, M., ROBERTS, C., POLS, J., DOMENECH, M. and MOSER, I.: Ethical implications of home telecare for older people: a framework derived from a multisited participative study. Health Expectation Health Expect. 8, 3, 2013, 438-49.

[28] NURMELA, J., PARJO, L. and SIRKIÄ T.: From Citizen to eCitizen. Results from Statistical Surveysabout Finns Use of ICT 1996-2005, 2004.. Reviews 2006/3, Helsinki: Statistics Finland, 2004.

[29] OECD, OECD Digital Economy Outlook 2015, OECD Publishing, Paris, 2015. DOI:10.1787/9789264232440-en.

[30] OSATUYI, B.: Information sharing on social media sites. Computers in Human Behavior. 29, 2013, 2622-2631.

[31] PEREIRA, G. C., ROCHA, M.C.F. and POPLIN, A.: e-Participation: Social Media and the Public Space. B. Murgante et al. (Eds.): ICCSA 2012, Part I, LNCS 7333. Springer-Verlag Berlin Heidelberg, 2012, 491-501.

[32] PWC, Global entertainment and media outlook 2014-2018, Annual Global CEO Survey, 2014.

[33] RONCHI, A. M: eCulture: cultural content in the digital age. Springer Science \& Business Media. New York, USA, 2009.

[34] SELWYN, N.: Reconsidering political and popular understanding of the digital divide. New Media \& Society, 6, 2004, 341-362.

[35] SHIH, C.-F. and VENKATESH, A.: Beyond Adoption: Development and Application of a Use-Diffusion Model. Journal of Marketing. 68, 1, 2004, 59-72. 
[36] SVENDSEN, L., P. and MONDAHL, E., M.: How social-media enhancedlearning platforms supportstudents in taking responsibilityfor their own learning. Journal of Applied Research in HigherEducation. 5, 2, 2013, 261-272.

[37] TAS, E. M: ICT education for development - a case study. Procedia Computer Science. 3, 2011, 507-512.

[38] VAN DIJK, J.: The network society. Social aspects of new media.Thousand Oaks. CA: Sage. London, UK, 1999. 
